\title{
The Local Inflammatory Responses to Infection of the Peritoneal Cavity in Humans: Their Regulation by Cytokines, Macrophages, and Other Leukocytes
}

\author{
Marien Willem Johan Adriaan Fieren \\ Department of Internal Medicine, Erasmus Medical Center, Centrumlocatie, P.O. Box 2040, 3000 CA Rotterdam, The Netherlands \\ Correspondence should be addressed to Marien Willem Johan Adriaan Fieren, m.fieren@erasmusmc.nl
}

Received 11 September 2011; Accepted 16 November 2011

Academic Editor: Markus Wornle

Copyright (C) 2012 Marien Willem Johan Adriaan Fieren. This is an open access article distributed under the Creative Commons Attribution License, which permits unrestricted use, distribution, and reproduction in any medium, provided the original work is properly cited.

\begin{abstract}
Studies on infection-induced inflammatory reactions in humans rely largely on findings in the blood compartment. Peritoneal leukocytes from patients treated with peritoneal dialysis offer a unique opportunity to study in humans the inflammatory responses taking place at the site of infection. Compared with peritoneal macrophages $(\mathrm{pM} \phi)$ from uninfected patients, $\mathrm{pM} \phi$ from infected patients display ex vivo an upregulation and downregulation of proinflammatory and anti-inflammatory mediators, respectively. Pro-IL-1 $\beta$ processing and secretion rather than synthesis proves to be increased in $\mathrm{pM} \phi$ from infectious peritonitis suggesting up-regulation of caspase-1 in vivo. A crosstalk between $\mathrm{pM} \phi, \gamma \delta \mathrm{T}$ cells, and neutrophils has been found to be involved in augmented TNF $\alpha$ expression and production during infection. The recent finding in experimental studies that alternatively activated macrophages $(\mathrm{M} \phi 2)$ increase by proliferation rather than recruitment may have significant implications for the understanding and treatment of chronic inflammatory conditions such as encapsulating peritoneal sclerosis (EPS).
\end{abstract}

\section{Introduction}

Continuous ambulatory peritoneal dialysis (CAPD) was introduced in 1978 as a new treatment modality for patients with end-stage renal failure. In CAPD, after infusion of typically 2 litres of dialysis fluid via a catheter into the peritoneal cavity, retained metabolites diffuse from the blood to the peritoneal cavity during a dwell time of 4 to 8 hours, after which the dialysis fluid is drained and replaced with fresh dialysis fluid. In this way, the patient exchanges 3-5 times a day dialysis fluid. A major complication of CAPD is peritonitis caused by contamination by microorganisms that can enter the peritoneal cavity via infusion of dialysis fluid during the exchange, or by spreading of an infection from the skin and tissue around the catheter to the peritoneal cavity, or from the intestines [1]. In the early years, an episode of peritonitis occurred on average one time per 8 treatment months, but since the nineties the frequency was substantially reduced to one time every 24 months due to novel connections of the infusion systems. These so-called "flush-before-fill" systems reduce the risk of peritonitis during the exchange of dialysis fluids, which is caused especially by coagulase negative Staphylococci and other gram positive microorganisms. Infectious peritonitis is characterized by abdominal pain and turbid drained dialysate (peritoneal effluent) due to an increased number of leukocytes more than $50 \%$ of which are neutrophilic PMN's. Peritonitis is almost invariably revealed by opalescence of dialysate, which is noticed by patients when the leucocyte count is greater than $100 / \mathrm{mm}^{3}$. The majority of peritonitis episodes can be treated successfully with the intraperitoneal administration of antibiotics while continuing CAPD.

Infectious peritonitis in CAPD patients has been shown to provide a unique opportunity to study the inflammatory reactions in humans at the site of inflammation by studying cellular players including macrophages, lymphocytes, granulocytes, and mesothelial cells as well as soluble mediators present in peritoneal effluent [2-4]. In this paper, various studies are reviewed that are conducted in the past few decades on this topic with emphasis on the role of 
macrophages $(\mathrm{M} \phi)$ and cytokines. The findings will be put in the context of new insights that developed the past decade in the biology of $\mathrm{M} \phi$ and cytokines. Studying leukocytes from an inflammatory environment can make a valuable contribution to a better understanding of inflammatory reactions in humans.

\section{Macrophages, Heterogeneity versus Polarization}

Tissue $\mathrm{M} \phi$ are derived from circulating blood monocytes, which in turn arise from their bone marrow precursors. These cells together make up the mononuclear phagocyte system, as described by van Furth and Cohn [5]. After monocytes have entered the tissues to become $M \phi$, they have the potential to acquire a variety of different functional attributes depending on signals they receive from the environment. Thus, the mononuclear phagocyte system consists of a heterogeneous and highly versatile, multipotential cell population. The differentiation and activation to diverse functions in the tissues are governed by the presence of regulatory signals in the environment and occur in several distinct steps [6]. In the past decade, a new view on $\mathrm{M} \phi$ differentiation and activation has been developed. In vitro two types of $\mathrm{M} \phi$ are distinguished: Classically activated $\mathrm{M} \phi$ display a proinflammatory profile, induced by IFN- $\gamma$ or LPS, whereas alternatively activated $\mathrm{M} \phi$ express anti-inflammatory and tissue repair properties induced by IL-4 or IL-13 [7-11]. IFN$\gamma$ is a prototypical Th-1 cell secretory product, while IL-4 and IL-13 are produced by Th- 2 cells and M $\phi$. Classically and alternatively activated $\mathrm{M} \phi$ are also named as $\mathrm{M} \phi 1$ and $\mathrm{M} \phi 2$, mirroring the Th- 1 and Th-2 polarization, respectively. Type 1 and type 2 inflammation represent ancient innate pathways with fundamentally different purposes. Type 1 promotes killing of microbial pathogens and intracellular parasites and is involved in tissue destruction and tumor resistance. Type 2 participates in tissue repair and controls infection with macroparasites through encapsulation. $\mathrm{M} \phi 1$ typically show a high expression of the cytokines IL-12, IL-23, TNF $\alpha$, IL- $1 \beta$, and $M \phi 1$ chemokines and are efficient producers of reactive oxygen and nitrogen intermediates, whereas IL10 production is low. In contrast, in $\mathrm{M} \phi 2$ expression of IL-12, IL-23, TNF $\alpha$, and IL- $1 \beta$ is low, whereas expression of IL-10, IL-1ra, TGF $\beta, \mathrm{M} \phi 2$ chemokines and scavenger, mannose and galactose receptors is high. In experimental in vivo studies, it has been found that a subset of patrolling, circulating monocytes, which may correspond to human CD16+ monocytes, are rapidly recruited to the peritoneal cavity, peaking at 2 hours after infection with Listeria monocytogenes, when PMN is only beginning to enter the peritoneal cavity [12]. After 1 and 2 hours after infection these mononuclear phagocytes produce TNF $\alpha$ and show an upregulated expression of genes coding for IL- 1 and various chemokines and pattern recognition receptors such as tolllike receptors (TLRs). Notably, the production of TNF $\alpha$ and IL- $1 \beta$ is transient and turns off at 8 hours, whereas these mononuclear phagocytes turn on, at 2 and 8 hours, in genes involved in tissue remodeling. A different subset

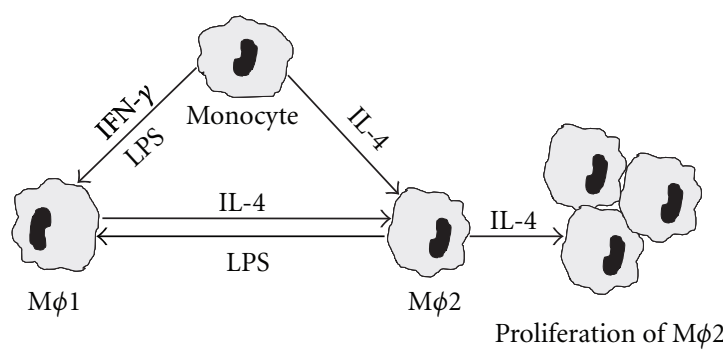

- Tissue destruction
- Killing of microorganisms
- Proinflammatory cytokines

- Tissue repair

- Encapsulation

- Anti-inflammatory cytokines

FIgURE 1: Simplified model of the paradigm of polarized macrophage activation. Monocytes are either classically $(\mathrm{M} \phi 1)$ or alternatively $(\mathrm{M} \phi 2)$ activated. Substances such as IFN- $\gamma$ and LPS induce classical activation while IL-4, IL-13, and TGF $\beta$ cause alternative activation. $\mathrm{M} \phi 1$ macrophages typically produce high levels of proinflammatory proteins including TNF $\alpha$, IL-1 $\beta$, IL-12, and IL-23 as well as reactive oxygen and nitrogen intermediates. $\mathrm{M} \phi 2$ produce high levels of the anti-inflammatory cytokines IL-10 and IL-1ra and show a high expression of scavenger and mannose receptors. Under the influence of IL- $4, \mathrm{M} \phi 2$ can accumulate in tissues by local proliferation rather than by recruitment. Either functional phenotype can shift to another depending on microenvironmental influences, speaking against rigid interpretation of the dichotomy between the macrophage phenotypes.

of conventional monocytes arrive later and give rise to inflammatory dendritic cells (DCs) and $\mathrm{M} \phi 1$ macrophages $[8,12]$. In a recent experimental study, it was found that both resident and recruited $\mathrm{M} \phi$ can be alternatively activated and be driven to proliferate in situ by a Th-2 environment in vivo, implying that there is neither a specific precursor for $\mathrm{M} \phi 2$ nor is proliferative capacity restricted by lineage [13]. While the paradigm of macrophage dichotomy is well established, employing it as a rigid scheme could bring about a risk of oversimplification. Thus, $\mathrm{M} \phi$ can reversibly shift their functional phenotype through a multitude of patterns in response to changes in cytokine environment, as illustrated in Figure 1 [14]. In humans, arginase, which is considered to be characteristic of alternatively activated macrophages, is not expressed prominently IL-4-induced $\mathrm{M} \phi 2$ macrophages [15]. Furthermore, during the resolution phase of experimental inflammation a $\mathrm{M} \phi$ phenotype with properties of both $\mathrm{M} \phi 1$ and $\mathrm{M} \phi 2$ could be distinguished [16].

\section{Peritoneal Macrophage (pM $\phi$ ) from CAPD Patients}

Approximately 1-40 millions of leukocytes can be collected from peritoneal effluent after a dwell time of 68 hours. The yield decreases in the course of CAPD treatment. In uninfected patient, the leukocyte population was found to be composed of $85 \%$ mononuclear phagocytes by nonspecific esterase staining, while $>75 \%$ of each cell population was HLA-DR+. Six percent were neutrophilic 
and/or eosinophilic PMNs [17, 18]. Using flow cytometric analysis for surface markers, about $40 \%$ of the peritoneal cells were identified as lymphocytes [19]. Various subsets are distinguished in peritoneal lymphocytes including B cells and various subsets of T cells. Two to six percent of peritoneal cells can be characterized as DC's, which are differentiated in the peritoneal cavity from monocyte-derived CD14+ cells $[20,21]$. Peritoneal CD14+ cells were characterized as $\mathrm{M} \phi 2$ macrophages on the basis of a CD163+CD16phenotype, a high capacity for phagocytosis and production of high amounts of IL-10, sharing these properties with in vitro polarized $\mathrm{M} \phi 2$ [19]. In contrast, the production of substantial amounts of IL-6, as found in this study, is a property of $M \phi 1$ rather than $M \phi 2$. The CAPD cell population is continually renewed and is exposed to dialysis fluids with an unphysiological composition and to the dialysis catheter. Yet, in many respects the macrophages from CAPD patient bear resemblance to those from healthy women undergoing laparoscopy $[17,18]$. Compared with such cells from rats, CAPD $\mathrm{pM} \phi$ resemble starch-elicited rather than resident cells [22].

When a peritoneal infection becomes clinically manifest, there is a sharp, up to 100 fold increase in peritoneal leukocytes, $50-90 \%$ of which are neutrophils. Also the number of $\mathrm{pM} \phi$, dendritic cells and various subsets of lymphocytes show a marked increase, including $\gamma \delta \mathrm{T}$ cells $[20,23]$. This minisubset is rapidly recruited to the inflammatory site and responds to the microbial molecule HMB-PP that is found in various species-30\% to $50 \%$ of peritonitis episodes is caused by HMB-PP+ microbes-and is released when microorganisms are killed by other leukocytes including neutrophils [24]. By interaction of $\gamma \delta \mathrm{T}$ cells with mononuclear phagocytes, the inflammatory reaction is amplified. Already one to two days before the infection becomes clinically manifest, an increased number of $\mathrm{pM} \phi$ and neutrophils is found [25]. Following appropriate antibiotic treatment, the mononuclear cells and especially the neutrophils show a sharp drop in the next few days, resulting in a relative increase of $\mathrm{pM} \phi$ and lymphocytes. While on the first day of the peritonitis $\mathrm{pM} \phi$ outnumber lymphocytes, in the resolution phase the macrophages/lymphocytes ratio is reversed [26]. Using flow cytometry, $\mathrm{pM} \phi$ from infected patients displayed an increased expression and production of selected $\mathrm{M} \phi 2$-associated cell surface markers (CD163+) and chemokines (CCL18), respectively, but expression of the $\mathrm{M} \phi 2$-associated mannose receptor CD206+ was lower in peritonitis $\mathrm{pM} \phi$. Gene expression of TGF- $\beta 1$, metalloproteinase 9 (MMP9), and CCL18 in $\mathrm{pM} \phi$ from infected and uninfected patients were similar [27].

\section{Cytokines in CAPD during Infectious Peritonitis}

The pro-inflammatory cytokines IL- $1 \beta$, TNF $\alpha$, and IL-6 play a key role in the inflammatory response. By exerting their pleiotropic effects in an autocrine, paracrine, and endocrine fashion, these cytokines are able to orchestrate the inflammatory responses. Although they can be produced by various cells, macrophages are the prototypical cell source. PM $\phi$ from CAPD patients collected during infectious peritonitis, showed a marked increase in the secretion of TNF $\alpha$ and IL-1 $\beta$ as compared with macrophages from infection free patients, when they were stimulated ex vivo with LPS $[28,29]$. In contrast, unstimulated $\mathrm{pM} \phi$ secreted similar amounts of TNF $\alpha$ and IL- $1 \beta$ ex vivo in $\mathrm{pM} \phi$ from patients with and without infection. These findings are in line with the paradigm of stepwise activation of $\mathrm{M} \phi$. On the other hand, the ex vivo secretion of the anti-inflammatory IL-10 was decreased in peritonitis macrophages, in line with a pro-inflammatory phenotype [30]. In the effluent from patients with infectious peritonitis, as compared with uninfected patients, increased levels of various pro-inflammatory cytokines were found, including IL-1 $\beta$, IL-8, TNF $\alpha$, IL-6, and IFN $\gamma[26,31-35]$. Remarkably, also levels of anti-inflammatory cytokines for example, TGF $\beta$ and IL-1ra were elevated $[26,32,36]$. It should be noted that in addition to $\mathrm{M} \phi$ and other leukocytes, mesothelial cells may also contribute substantially to the production of various cytokines including IL- 6 and IL-8 [37, 38].

We investigated at which level the increased capability of peritonitis $\mathrm{pM} \phi$ to secrete IL- $1 \beta$ after ex vivo stimulation with LPS occurs, using ELISA's specific to the $32 \mathrm{kDa}$, biologically inactive pro-IL- $1 \beta$ and the mature $17 \mathrm{kDa}$, bioactive IL-1 $\beta$ [39]. Pro-IL- $1 \beta$ processing and subsequent release of mature IL- $1 \beta$ (mIL-1 $\beta$ ) rather than its production were found to be increased in peritonitis $\mathrm{pM} \phi$ (Figures $2(\mathrm{a}), 2(\mathrm{~b})$, and 2(c)), suggesting increased caspase-1 activity. Caspase-1 is present in the cell as the bioinactive procaspase-1 to become a bioactive cysteine protease after autocleavage. In the last decade, the understanding of the molecular mechanisms behind caspase- 1 activation has been significantly increased. Briefly, NOD-like receptors (NLRs), present in the cytosol, recognize microbial molecules leading to oligomerization of NLRs and along with recruited procaspase- 1 and other proteins, to the forming of multiprotein inflammasome complexes [40]. This results in auto-cleavage and activation of caspase- 1 , whereupon pro-IL- $1 \beta$ is cleaved and $\mathrm{mIL}-1 \beta$ is released by an unconventional, poorly understood, mechanism as IL- $1 \beta$ lacks a signal peptide [41]. Microbial ligands induce transcription of pro-IL$1 \beta$ and inflammasome components by activation of the transmembrane TLRs. Taken together, in the setting of our study increased caspase- 1 activation might be postulated as priming mechanism in vivo. Interestingly, in a study using high-density oligonucleotide microarrays to investigate the transcriptional profile induced in human monocytes by IL-13, one the most striking findings, besides a variety of other characteristic genetic markers of alternatively activated macrophages, was downregulation of caspase-1 and changes in other components of the IL- 1 system such as up-regulation of IL-1ra [15]. The LPS-inducible caspase-1 activity was also found to be reduced, resulting in a decrease in pro-IL- $1 \beta$ processing. Further studies are needed to reveal which molecular mechanisms account for the increased IL$1 \beta$ processing and export in peritonitis $\mathrm{pM} \phi$. We also found that LPS stimulated not only pro-IL- $1 \beta$ production but also release of $\mathrm{mIL}-1 \beta$ in a dose-dependent fashion, suggesting 

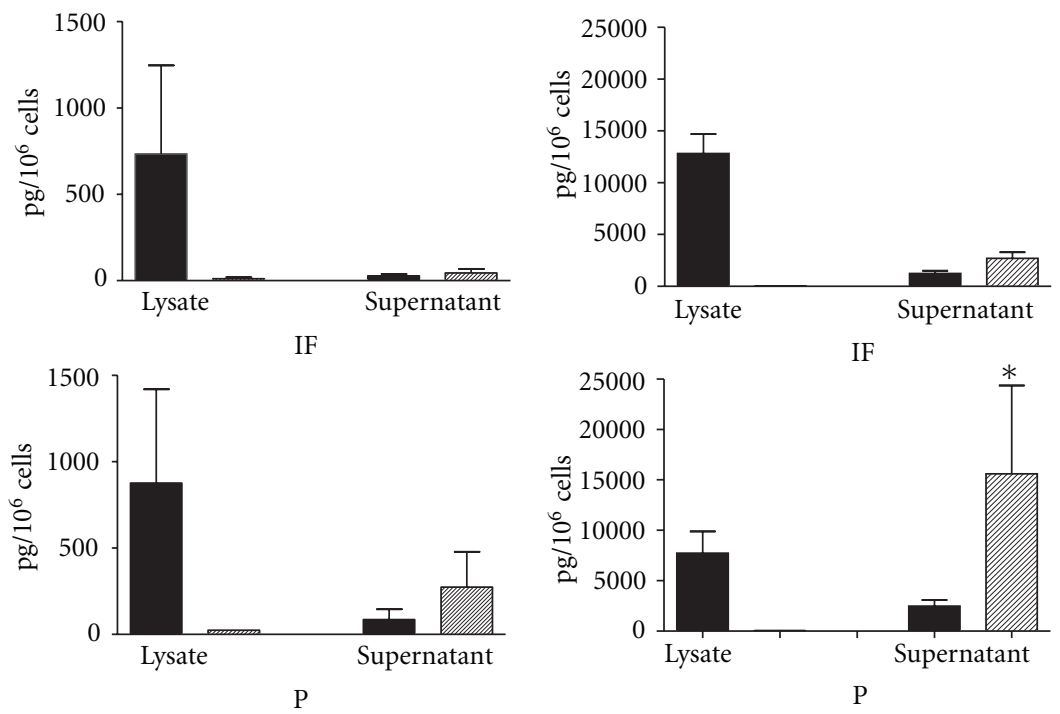

- Pro-IL-1 $\beta$

ㄴ. $\mathrm{mIL}-1-\beta$

- Pro-IL-1 $\beta$

mIL-1- $\beta$

(b)
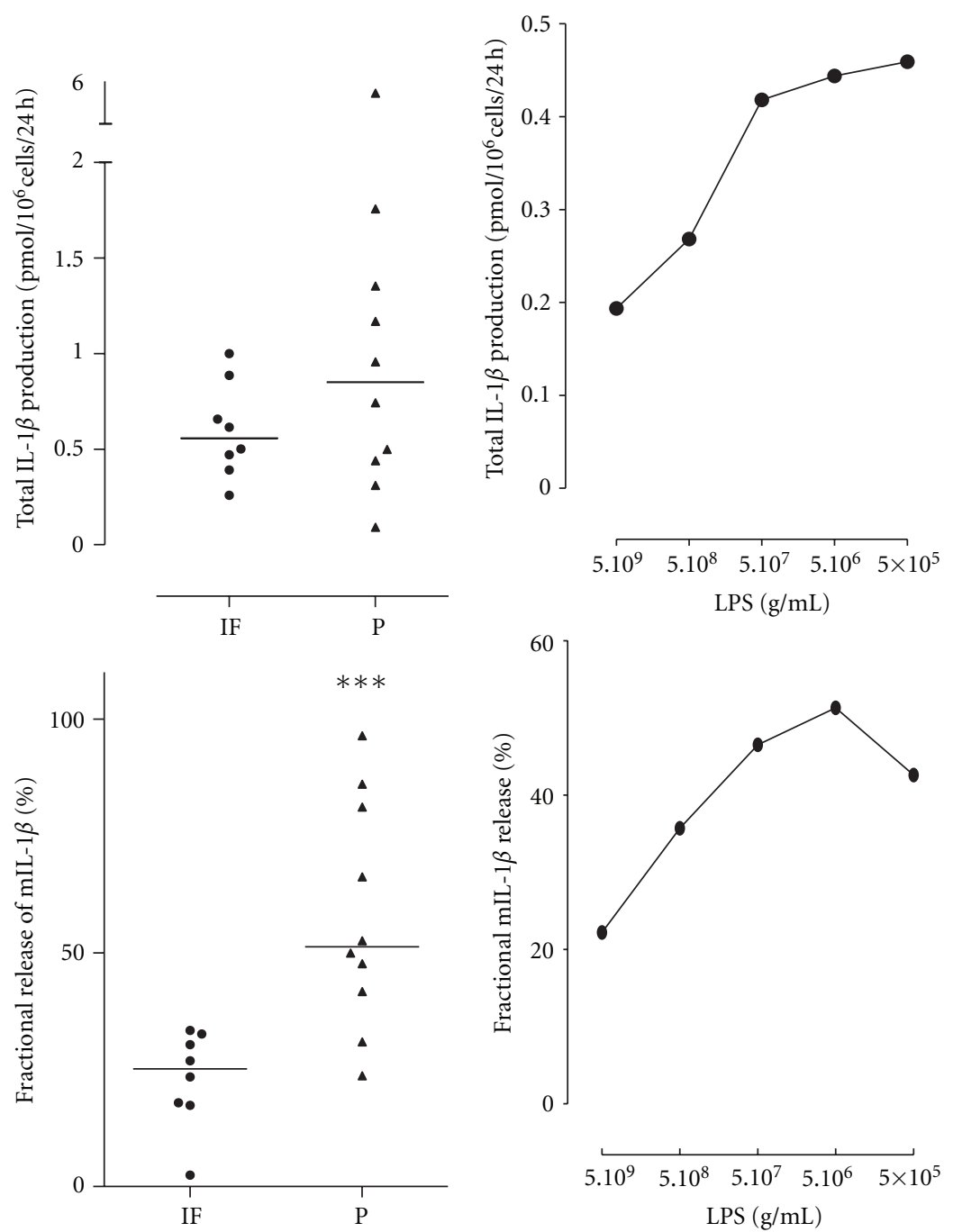

(c)

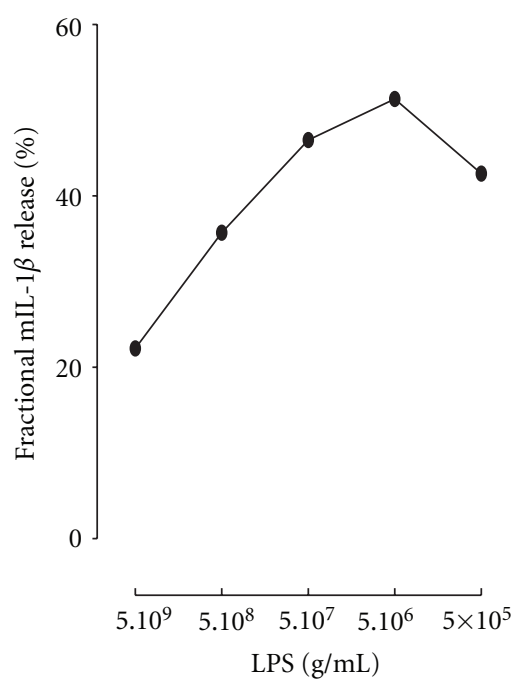

(d)

Figure 2: Continued. 

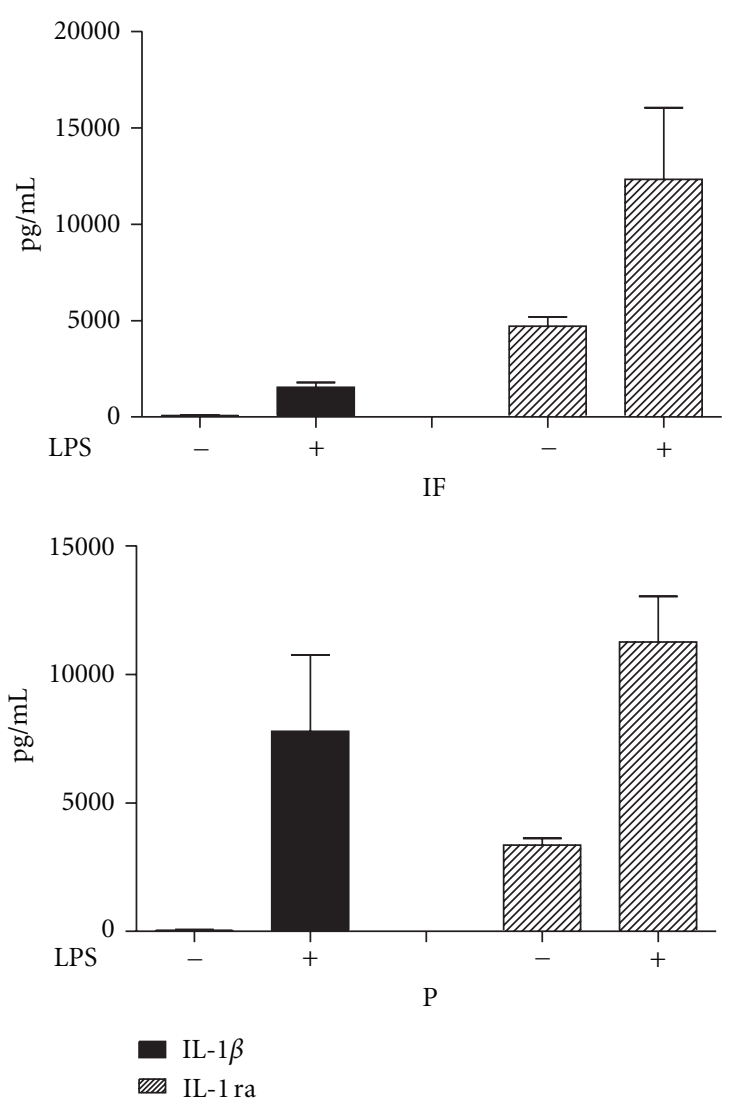

(e)

Figure 2: Peritoneal macrophages $(\mathrm{pM} \phi)$ were isolated from CAPD patients who were at least 3 months infection free (IF), or during an episode of infectious peritonitis $(\mathrm{P})$, prior to the start of treatment with antibiotics. $1.10^{6}$ Cells were incubated ex vivo during $24 \mathrm{~h}$ in medium or $5 \mu / \mathrm{mL}$ of LPS. Cytokines were determined in supernatants or cell lysates using ELISA. (a) Pro-IL- $1 \beta$ production and processing and mIL- $1 \beta$ release. Quantities of pro-IL- $1 \beta$ (black bars) and mature IL- $1 \beta$ (mIL-1 $\beta$ ) (white bars), expressed in pg/10 cells $/ 24 \mathrm{~h}$, using ELISA specific for either form of IL- $1 \beta\left(\right.$ CISTRON $\left.^{\mathrm{R}}\right)$, in supernatants and cell lysates from pM $\phi$ isolated during IF-period $(n=8)$ or P $(n=10)$ and incubated in medium alone (a) or $5 \mu / \mathrm{mL}$ of LPS (b). Values are expressed as $(\mathrm{M} \pm \mathrm{SEM})$. mIL- $1 \beta$ levels in supernatants from LPS-stimulated $\mathrm{pM} \phi$ s were significantly higher when cells were isolated during $\mathrm{P}(P<0.05)$, while pro-IL- $1 \beta$ in cell lysates was decreased $(P \approx 0.05)$. (c) total IL- $\beta$ production (= pro-IL- $1 \beta+$ mIL- $1 \beta$ in supernatants + cell lysates) expressed in $\mathrm{pmol} / 10^{6} \mathrm{cells} / 24 \mathrm{~h}$ for each IF-period (circles) and P episode (triangles) in LPS stimulated $\mathrm{pM} \phi$. Difference between total IL- $1 \beta$ production from IF and P pM $\phi$ was not statistically significant. fraction of total IL- $1 \beta$ that is released in supernatant as mIL- $1 \beta$, expressed as percentage. Fractional release from peritonitis $\mathrm{pM} \phi$ was significantly higher $(P<0.005)$. (d) total IL- $1 \beta$ production and fractional mIL- $1 \beta$ release in response to increasing doses of LPS in $\mathrm{pM} \phi$ isolated during 3 episodes of peritonitis, expressed in pmol/10 $\mathrm{cells} / 24 \mathrm{~h}$. Total IL- $1 \beta$ production increased in a dosedependent fashion. Within the range of $5 \cdot 10^{-9}-5 \cdot 10^{-6} \mathrm{~g} / \mathrm{mL}$, LPS induced a dose-related increase in fractional IL- $1 \beta$ release. (e) release of IL- $1 \beta$ and IL-1ra in supernatants from infection-free $(n=15)$ and peritonitis $\mathrm{pM} \phi(n=8)$ stimulated with and without $5 \mu \mathrm{g} / \mathrm{mL}$ of LPS. Substantial amounts of IL-1ra were released in unstimulated cells. LPS-stimulated peritonitis pM $\phi$ released similar quantities of IL- $1 \beta$ and IL-1ra.

a stimulating effect of LPS on caspase-1 activity. (Figure 2(d)) $\mathrm{PM} \phi$ displayed a rather high constitutive production of IL-1ra that further increased by stimulation with LPS, with $\mathrm{pM} \phi$ from infection-free and peritonitis patients releasing similar amounts (Figure 2(e)). It has been reported that a $10-500$ fold molecular excess of IL-1ra is required to obtain $50 \%$ inhibition of IL-1 biological effects in vitro [42]. In our study, similar amounts of IL-1ra and IL- $1 \beta$ were released in LPS-stimulated peritonitis $\mathrm{pM} \phi$ implying a virtually unimpeded secreted IL-1 bioactivity. There was no production of the bioactive form of IL-12 (Figure 3(a)).
The secretion of the anti-inflammatory cytokine IL-10 by LPS-stimulated peritonitis $\mathrm{pM} \phi$ was significantly reduced (Figure 3(b)). However, IL-10 levels in peritoneal effluent were higher during peritonitis. The large increase in macrophages and other leukocytes during peritonitis, probably accounts for the discrepancy in the direction of the changes of IL-10 and other anti-inflammatory cytokines between macrophage cultures and peritoneal effluents. Absorption of pro- and anti-inflammatory cytokines from the infectious inflammatory site might offer in part an explanation for the discrepancy in the blood compartment 


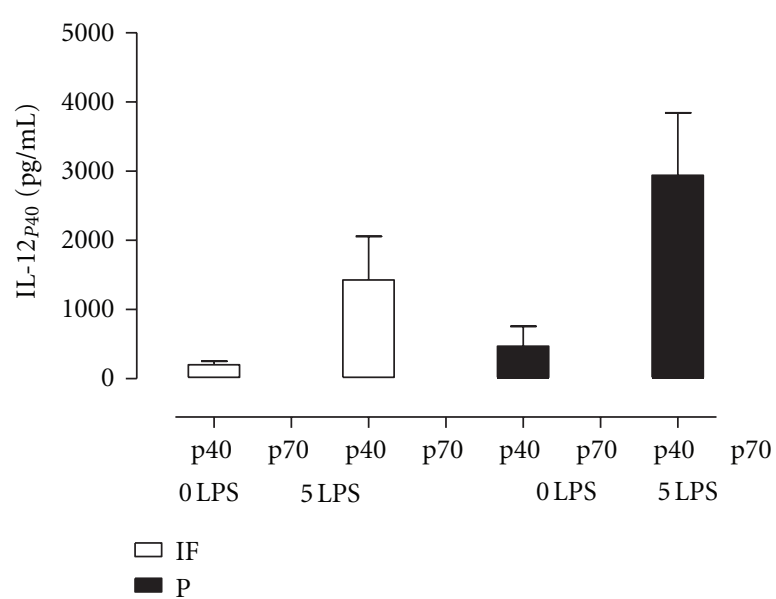

(a)

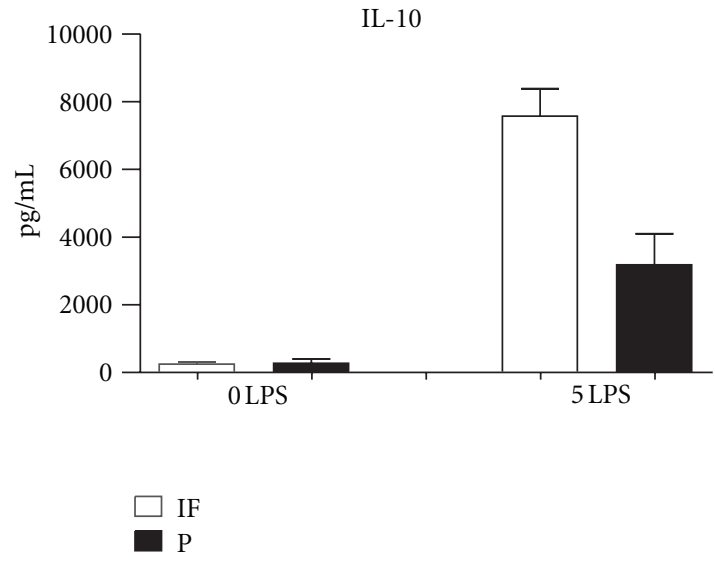

(b)

Figure 3: (a) Patients and methods as in Figure 1. Ex vivo IL- $12_{\mathrm{p} 40}$ release is stimulated by LPS. Difference between pM $\phi$ from an infectionfree period $(n=8)$ and an episode of peritonitis $(n=8)$, was statistically not significant. Using an ELISA specific to the bioactive, heterodimeric IL- $12_{\mathrm{p} 70}$, no active IL-12 was detectable in supernatants from uninfected patients $(n=5)$ nor in those with peritonitis $(n=5)$, whether or not the cells were stimulated with LPS. Consistent with this finding, virtually no IL-12 ${ }_{\mathrm{p} 35}$ mRNA was expressed (data not shown). All peritonitis episodes were caused by gram positive bacteria. (b) ex vivo IL-10 release from pM $\phi$ from infected patients $(n=8)$ is decreased as compared with $\mathrm{pM} \phi$ from an infection free environment $(n=8),(P<0.01)$. IL-10 levels in peritoneal effluents from peritonitis were higher compared with infection-free effluents, $235 \mathrm{pg} / \mathrm{mL}$ and $25 \mathrm{pg} / \mathrm{mL}$, respectively (data not shown in figure).

between higher levels of circulating pro-inflammatory cytokines and a decreased capacity of blood monocytes to secrete TNF $\alpha$ and IL- $1 \beta$ as found in patients with sepsis. Compartmentalization of the inflammatory response is a key feature of the sepsis syndrome [43].

$\operatorname{PM} \phi$ from infected patients have also an increased capability to release TNF $\alpha$ [29]. $\mathrm{PGE}_{2}$ has been found to have strongly inhibitory effects on LPS-stimulated TNF $\alpha$ release, almost eliminating the actions of LPS in a clearly doserelated fashion, whereas cyclooxygenase inhibition caused an increase in $\mathrm{TNF} \alpha$ release [44]. The $\mathrm{PGE}_{2}$-induced downregulation, which was similar for $\mathrm{pM} \phi$ from an infectious or infection-free environment, is probably brought about via elevation of intracellular cAMP levels. Moreover, it has been found that peritonitis macrophages have suppressed cAMP levels and a diminished release of prostaglandins compared to uninfected macrophages $[45,46]$. Similarly, ex vivo stimulation of $\mathrm{pM} \phi$ from uninfected patients with Staphylococcus epidermidis induced a marked decrease of cyclooxygenase products [47]. Prostaglandins are known for their pro-inflammatory effects, notably on the vascular components of inflammatory reactions, but in various settings these short-lived and locally acting substances have proved to possess anti-inflammatory properties as well. Recently it was reported, that, using low-dose and high-dose zymosan induced peritonitis as a model for self-limiting, resolving inflammation, and a more protracted response leading to systemic inflammation, respectively, $\mathrm{pM} \phi$ from either environment displayed distinct characteristics [16]. $\mathrm{PM} \phi$ from the protracted peritonitis had a typical $\mathrm{M} \phi 1$ phenotype, while those from the resolving inflammation had characteristics of both $M \phi 1$ and $M \phi 2$ and were named as resolving macrophages $(\mathrm{rM} \phi)$. These $\mathrm{rM} \phi$, as compared with $\mathrm{M} \phi 1$, released ex vivo fewer pro-inflammatory cytokines, including TNF $\alpha$, IL- $1 \beta$, and IL-12 but more IL- 10 and $\mathrm{PGD}_{2}$. The expression of COX 2, iNOS, and intracellular cAMP contents were also increased. Elevating cAMP levels by cAMP analoga transformed $\mathrm{M} \phi 1$ to $\phi \mathrm{M}$, whereas cAMP inhibitors converted $\mathrm{rM} \phi$ to $\mathrm{M} \phi 1$. These findings demonstrate that cAMP plays a central role in the regulation of $\mathrm{M} \phi$ phenotype. In addition, it has been found that cyclooxygenase inhibition improved bacterial killing and resistance to infection in mice and humans, confirming the important role of cAMP. Interestingly, COX 1 rather than COX 2 turned out to be the predominant form that is active during infection [48]. Similarly, phagocytosis of apoptotic cells by $\mathrm{M} \phi$ proved to inhibit the production of several mediators such as IL- $1 \beta$, $\mathrm{TNF} \alpha$, and IL-10, but it increased the production of TGF- $\beta 1$, $\mathrm{PGE}_{2}$, and PAF [49]. The latter mediators induced suppression of LPS-stimulated cytokine production by such $M \phi$. In contrast, indomethacin restored the inhibition of cytokines and inhibited TGF- $\beta 1$ production by phagocytosing $\mathrm{M} \phi$. These findings show that $\mathrm{PGE}_{2}$ along with TGF- $\beta 1$ and PAF plays an actively suppressing role in the shift from a proinflammatory to a more anti-inflammatory phenotype in $\mathrm{M} \phi$ that have ingested apoptotic cells.

\section{Conclusions and Future Perspectives}

Compared with $\mathrm{pM} \phi$ from uninfected CAPD patients, $\mathrm{pM} \phi$ from an infected peritoneal cavity display ex vivo an upregulation of production and secretion of pro-inflammatory cytokines and a downregulation of anti-inflammatory mediators. In terms of polarized macrophage activation, these 
findings show that during infectious peritonitis the $\mathrm{pM} \phi$ population is on average shifted to a $M \phi 1$ phenotype. In the above-mentioned studies, the cells were collected when the first signs and symptoms of peritonitis became manifest, that is, before antibiotic treatment was started. Following successful treatment, signs and symptoms improve within a few days. Ex vivo studies with effluents could also provide an unique opportunity to follow up human $\operatorname{pM} \phi$ and other leukocytes during the resolution phase, set in motion after antibiotics have brought about reduction and elimination of microbes. What changes do $\mathrm{pM} \phi$ and other leukocytes undergo in the recovery phase during the shift from $M \phi 1$ to a more typical $\mathrm{M} \phi 2$ profile? What is the time course and how long do $\mathrm{M} \phi 1$ features persist? Using current techniques including transcriptional profiling, proteomics and flow cytometry, a better understanding of the regulation of infection-induced inflammatory reactions in humans may be achieved. The findings of the comparative studies on cytokine release from $\mathrm{pM} \phi$ from an infection-free and infectious environment are in line with the postulate that in vivo $\mathrm{M} \phi 1$ and $\mathrm{M} \phi 2$ are extremes of a wide spectrum of phenotypes. Yet, the fact that $\mathrm{M} \phi 2$ may increase by local proliferation rather than by recruitment, as recently found in experimental studies, may have important implications for the way we look at the pathogenesis and therapy of chronic inflammatory disorders, if this interesting discovery also applies in humans $[13,50]$. Severe fibrosis and neoangiogenesis of the peritoneum are the histological hallmarks of encapsulating peritoneal sclerosis (EPS), a rare but serious complication of long-term CAPD [51-56]. Etiology and pathogenesis are incompletely understood, but EPS may be conceived as an extreme example of type 2 inflammation. Histological studies and ex vivo studies of $\mathrm{pM} \phi$ from peritoneal effluents, assuming they are representative of peritoneal tissue $\mathrm{M} \phi$, may help to gain a better understanding of this complication.

\section{References}

[1] P. K. T. Li, C. C. Szeto, B. Piraino et al., "Peritoneal dialysisrelated infections recommendations: 2010 update," Peritoneal Dialysis International, vol. 30, no. 4, pp. 393-423, 2010.

[2] M. W. J. A. Fieren, "Mechanisms regulating cytokine release from peritoneal macrophages during continuous ambulatory peritoneal dialysis," Blood Purification, vol. 14, no. 2, pp. 179187, 1996.

[3] N. Topley, R. K. Mackenzie, and J. D. Williams, "Macrophages and mesothelial cells in bacterial peritonitis," Immunobiology, vol. 195, no. 4-5, pp. 563-573, 1996.

[4] G. W. Roberts, D. Baird, K. Gallagher et al., "Functional effector memory $\mathrm{T}$ cells enrich the peritoneal cavity of patients treated with peritoneal dialysis," Journal of the American Society of Nephrology, vol. 20, no. 9, pp. 1895-1900, 2009.

[5] R. van Furth and Z. A. Cohn, "The origin and kinetics of mononuclear phagocytes," Journal of Experimental Medicine, vol. 128, no. 3, pp. 415-435, 1968.

[6] S. Gordon, "The macrophage: past, present and future," European Journal of Immunology, vol. 37, supplement 1, pp. S9S17, 2007.
[7] F. Geissmann, S. Jung, and D. R. Littman, "Blood monocytes consist of two principal subsets with distinct migratory properties," Immunity, vol. 19, no. 1, pp. 71-82, 2003.

[8] F. Geissmann, M. G. Manz, S. Jung, M. H. Sieweke, M. Merad, and K. Ley, "Development of monocytes, macrophages, and dendritic cells," Science, vol. 327, no. 5966, pp. 656-661, 2010.

[9] A. Varin and S. Gordon, "Alternative activation of macrophages: immune function and cellular biology," Immunobiology, vol. 214, no. 7, pp. 630-641, 2009.

[10] S. Gordon and F. O. Martinez, "Alternative activation of macrophages: mechanism and functions," Immunity, vol. 32, no. 5, pp. 593-604, 2010.

[11] A. Mantovani, A. Sica, and M. Locati, "New vistas on macrophage differentiation and activation," European Journal of Immunology, vol. 37, no. 1, pp. 14-16, 2007.

[12] C. Auffray, D. Fogg, M. Garfa et al., "Monitoring of blood vessels and tissues by a population of monocytes with patrolling behavior," Science, vol. 317 , no. 5838, pp. 666-670, 2007.

[13] S. J. Jenkins, D. Ruckerl, P. C. Cook et al., "Local macrophage proliferation, rather than recruitment from the blood, is a signature of $\mathrm{T}_{\mathrm{h}} 2$ inflammation," Science, vol. 332, no. 6035, pp. 1284-1288, 2011.

[14] R. D. Stout, C. Jiang, B. Matta, I. Tietzel, S. K. Watkins, and J. Suttles, "Macrophages sequentially change their functional phenotype in response to changes in microenvironmental influences," The Journal of Immunology, vol. 175, no. 1, pp. 342-349, 2005.

[15] C. J. Scotton, F. O. Martinez, M. J. Smelt et al., "Transcriptional profiling reveals complex regulation of the monocyte IL- $1 \beta$ system by IL-13," The Journal of Immunology, vol. 174, no. 2, pp. 834-845, 2005.

[16] J. Bystrom, I. Evans, J. Newson et al., "Resolution-phase macrophages possess a unique inflammatory phenotype that is controlled by cAMP," Blood, vol. 112, no. 10, pp. 4117-4127, 2008.

[17] C. S. Goldstein, J. S. Bomalaski, R. B. Zurier, E. G. Neilson, and S. D. Douglas, "Analysis of peritoneal macrophages in continuous ambulatory peritoneal dialysis patients," Kidney International, vol. 26, no. 5, pp. 733-740, 1984.

[18] Y. Maddox, M. Foegh, and B. Zeglis, "A routine source of human peritoneal macrophages," Scandinavian Journal of Immunology, vol. 19, no. 1, pp. 23-29, 1984.

[19] W. Xu, N. Schlagwein, A. Roos, T. K. van den Berg, M. R. Daha, and C. van Kooten, "Human peritoneal macrophages show functional characteristics of M-CSF-driven anti-inflammatory type 2 macrophages," European Journal of Immunology, vol. 37, no. 6, pp. 1594-1599, 2007.

[20] M. L. McCully, T. A. Chau, P. Luke, P. G. Blake, and J. Madrenas, "Characterization of human peritoneal dendritic cell precursors and their involvement in peritonitis," Clinical \& Experimental Immunology, vol. 139, no. 3, pp. 513-525, 2005.

[21] M. G. Betjes, C. W. Tuk, D. G. Struijk, R. T. Krediet, L. Arisz, and R. H. J. Beelen, "Antigen-presenting capacity of macrophages and dendritic cells in the peritoneal cavity of patients treated with peritoneal dialysis," Clinical \& Experimental Immunology, vol. 94, no. 2, pp. 377-384, 1993.

[22] I. L. Bonta, M. J. P. Adolfs, and M. W. J. A. Fieren, "Cyclic AMP levels and their regulation by prostaglandins in peritoneal macrophages of rats and humans," International Journal of Immunopharmacology, vol. 6, no. 6, pp. 547-555, 1984.

[23] M. Eberl, G. W. Roberts, S. Meuter, J. D. Williams, N. Topley, and B. Moser, "A rapid crosstalk of human $\gamma \delta$ T cells and monocytes drives the acute inflammation in bacterial 
infections," PLoS Pathogens, vol. 5, no. 2, Article ID e1000308, 2009.

[24] M. S. Davey, C.-Y. Lin, G. W. Roberts et al., "Human neutrophil clearance of bacterial pathogens triggers anti-microbial $\gamma \delta$ T cell responses in early infection," PLoS Pathogens, vol. 7, no. 5, Article ID e1002040, 2011.

[25] M. G. Betjes, C. W. Tuk, C. E. Visser et al., "Analysis of the peritoneal cellular immune system during CAPD shortly before a clinical peritonitis," Nephrology Dialysis Transplantation, vol. 9, no. 6, pp. 684-692, 1994.

[26] K. N. Lai, K. B. Lai, C. W. K. Lam, T. M. Chan, F. K. Li, and J. C. K. Leung, "Changes of cytokine profiles during peritonitis in patients on continuous ambulatory peritoneal dialysis," American Journal of Kidney Diseases, vol. 35, no. 4, pp. 644$652,2000$.

[27] T. Bellón, V. Martínez, B. Lucendo et al., "Alternative activation of macrophages in human peritoneum: implications for peritoneal fibrosis," Nephrology Dialysis Transplantation, vol. 26, no. 9, pp. 2995-3005, 2011.

[28] M. W. J. A. Fieren, G. J. C. M. van den Bemd, and I. L. Bonta, "Endotoxin-stimulated peritoneal macrophages obtained from continuous ambulatory peritoneal dialysis patients show an increased capacity to release interleukin$1 \beta$ in vitro during infectious peritonitis," European Journal of Clinical Investigation, vol. 20, no. 4, pp. 453-457, 1990.

[29] M. W. J. A. Fieren, G. J. C. M. van den Bemd, I. L. Bonta, and S. Ben-Efraim, "Peritoneal macrophages from patients on continuous ambulatory peritoneal dialysis have an increased capability to release tumour necrosis factor during peritonitis," Journal of Clinical and Laboratory Immunology, vol. 34, no. 1, pp. 1-9, 1991.

[30] M. W. J. A. Fieren, W. W. Mol, and W. Weimar, "Peritoneal macrophages from patients with peritonitis have a suppressed capacity to release the anti inflammatory cytokine il-10," Mediators of Inflammation, vol. 8, Supplement 1, p. S149, 1999.

[31] A. Brauner, B. Hylander, and B. Wretlind, "Interleukin-6 and interleukin- 8 in dialysate and serum from patients on continuous ambulatory peritoneal dialysis," American Journal of Kidney Diseases, vol. 22, no. 3, pp. 430-435, 1993.

[32] A. Brauner, B. Hylander, and B. Wretlind, "Tumor necrosis factor- $\alpha$, interleukin- $1 \beta$, and interleukin- 1 receptor antagonist in dialysate and serum from patients on continuous ambulatory peritoneal dialysis," American Journal of Kidney Diseases, vol. 27, no. 3, pp. 402-408, 1996.

[33] M. K. Dasgupta, M. Larabie, and P. F. Halloran, "Interferongamma levels in peritoneal dialysis effluents: relation to peritonitis," Kidney International, vol. 46, no. 2, pp. 475-481, 1994.

[34] H.-H. Wang and C.-Y. Lin, "Interleukin-12 and -18 levels in peritoneal dialysate effluent correlate with the outcome of peritonitis in patients undergoing peritoneal dialysis: implications for the type I/type II T-cell immune response," American Journal of Kidney Diseases, vol. 46, no. 2, pp. 328$338,2005$.

[35] M. G. Betjes, C. E. Visser, D. Zemel et al., "Intraperitoneal interleukin-8 and neutrophil influx in the initial phase of a CAPD peritonitis," Peritoneal Dialysis International, vol. 16, no. 4, pp. 385-392, 1996.

[36] A. Moutabarrik, I. Nakanishi, M. Namiki, and Y. Tsubakihara, "Interleukin-1 and its naturally occurring antagonist in peritoneal dialysis patients," Clinical Nephrology, vol. 43, no. 4, pp. 243-248, 1995.

[37] J. Witowski, A. Jörres, G. A. Coles, J. D. Williams, and N. Topley, "Superinduction of IL-6 synthesis in human peritoneal mesothelial cells is related to the induction and stabilization of IL-6 mRNA," Kidney International, vol. 50, no. 4, pp. 12121223, 1996.

[38] M. G. Betjes, C. W. Tuk, D. G. Struijk et al., "Interleukin-8 production by human peritoneal mesothelial cells in response to tumor necrosis factor- $\alpha$, interleukin- 1 , and medium conditioned by macrophages cocultured with Staphylococcus epidermidis," Journal of Infectious Diseases, vol. 168, no. 5, pp. 1202-1210, 1993.

[39] M. W. J. A. Fieren, W. W. Mol, C. C. Baan, and W. Weimar, "Pro-Il- $1 \beta$ processing and release rather than its production are increased in peritoneal macrophages from patients with infectious pertitonitis," Mediators Of Inflammation, vol. 8, Supplement 1, p. S14, 1999.

[40] M. Leslie, “Internal affairs," Science, vol. 326, no. 5955, pp. 929-931, 2009.

[41] J. Chin and M. J. Kostura, "Dissociation of IL- $1 \beta$ synthesis and secretion in human blood monocytes stimulated with bacterial cell wall products," The Journal of Immunology, vol. 151, no. 10, pp. 5574-5585, 1993.

[42] W. P. Arend, "Interleukin 1 receptor antagonist. A new member of the interleukin 1 family," Journal of Clinical Investigation, vol. 88, no. 5, pp. 1445-1451, 1991.

[43] J.-M. Cavaillon and D. Annane, "Compartmentalization of the inflammatory response in sepsis and SIRS," Journal of Endotoxin Research, vol. 12, no. 3, pp. 151-170, 2006.

[44] M. W. J. A. Fieren, G. J. C. M. van den Bemd, S. Ben-Efraim, and I. L. Bonta, "Prostaglandin $\mathrm{E}_{2}$ inhibits the release of tumor necrosis factor- $\alpha$, rather than interleukin $1 \beta$, from human macrophages," Immunology Letters, vol. 31, no. 1, pp. 85-90, 1992.

[45] M. W. Fieren, M. J. Adolfs, and I. L. Bonta, "Alterations in sensitivity and secretion of prostaglandins of human macrophages during CAPD-related peritonitis," Contributions to Nephrology, vol. 57, pp. 55-62, 1987.

[46] M. W. J. A. Fieren, G. J. C. M. van den Bemd, and I. L. Bonta, "Release of Interleukin-1 and prostaglandins from peritoneal macrophages," Prostaglandins Leukotrienes and Essential Fatty Acids, vol. 47, no. 1, pp. 23-28, 1992.

[47] R. K. Mackenzie, G. A. Coles, and J. D. Williams, "Eicosanoid synthesis in human peritoneal macrophages stimulated with S. epidermidis," Kidney International, vol. 37, no. 5, pp. 13161324, 1990.

[48] M. J. Stables, J. Newson, S. S. Ayoub, J. Brown, C. J. Hyams, and D. W. Gilroy, "Priming innate immune responses to infection by cyclooxygenase inhibition kills antibiotic-susceptible and -resistant bacteria," Blood, vol. 116, no. 16, pp. 2950-2959, 2010.

[49] V. A. Fadok, D. L. Bratton, A. Konowal, P. W. Freed, J. Y. Westcott, and P. M. Henson, "Macrophages that have ingested apoptotic cells in vitro inhibit proinflammatory cytokine production through autocrine/paracrine mechanisms involving TGF- $\beta$, PGE2, and PAF," Journal of Clinical Investigation, vol. 101, no. 4, pp. 890-898, 1998.

[50] G. J. Randolph, "Immunology: no need to coax monocytes," Science, vol. 332, no. 6035, pp. 1268-1269, 2011.

[51] J. D. Williams, K. J. Craig, N. Topley et al., "Morphologic changes in the peritoneal membrane of patients with renal disease," Journal of the American Society of Nephrology, vol. 13, no. 2, pp. 470-479, 2002.

[52] Y. Kawaguchi, A. Saito, H. Kawanishi et al., "Recommendations on the management of encapsulating peritoneal sclerosis in Japan, 2005: diagnosis, predictive markers, treatment, and 
preventive measures," Peritoneal Dialysis International, vol. 25, supplement 4, pp. S83-S95, 2005.

[53] A. M. Summers, M. J. Clancy, F. Syed et al., "Single-center experience of encapsulating peritoneal sclerosis in patients on peritoneal dialysis for end-stage renal failure," Kidney International, vol. 68, no. 5, pp. 2381-2388, 2005.

[54] M. W. J. A. Fieren, M. G. Betjes, M. R. Korte, and W. H. Boer, "Posttransplant encapsulating peritoneal sclerosis: a worrying new trend?" Peritoneal Dialysis International, vol. 27, no. 6, pp. 619-624, 2007.

[55] N. Braun, P. Fritz, D. Biegger et al., "Difference in the expression of hormone receptors and fibrotic markers in the human peritoneum-implications for therapeutic targets to prevent encapsulating peritoneal sclerosis," Peritoneal Dialysis International, vol. 31, no. 3, pp. 291-300, 2011.

[56] S. J. Davies, L. Mushahar, Z. Yu, and M. Lambie, "Determinants of peritoneal membrane function over time," Seminars in Nephrology, vol. 31, no. 2, pp. 172-182, 2011. 


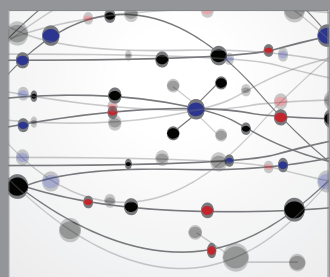

The Scientific World Journal
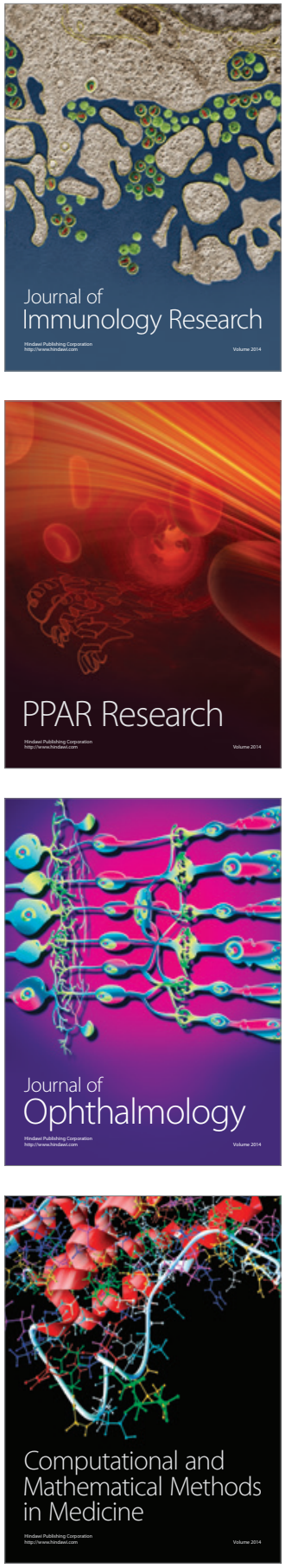

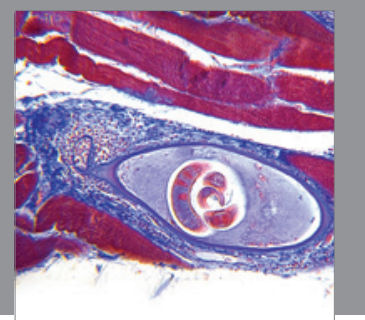

Gastroenterology

Research and Practice
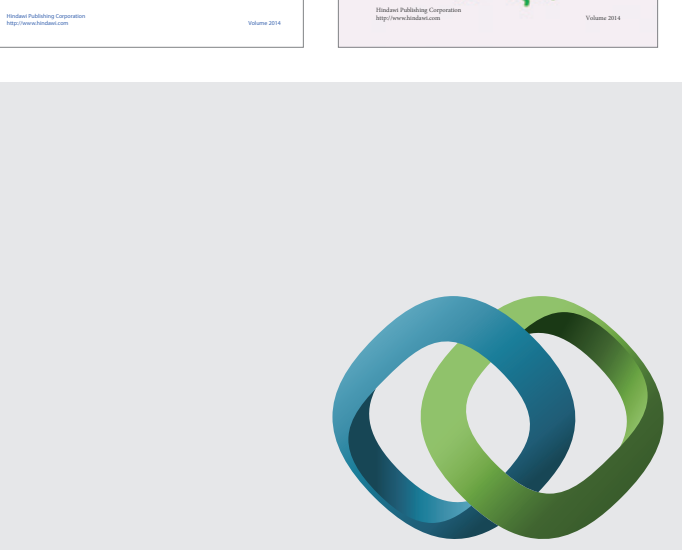

\section{Hindawi}

Submit your manuscripts at

http://www.hindawi.com
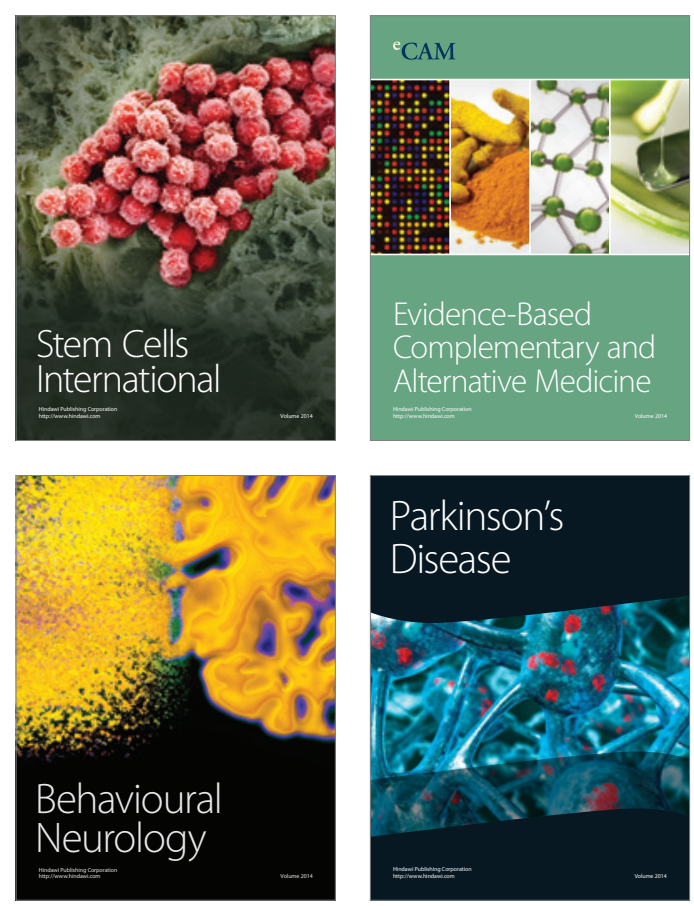

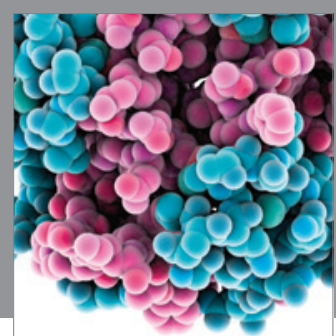

Journal of
Diabetes Research

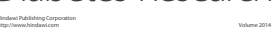

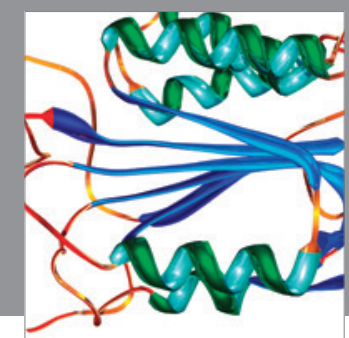

Disease Markers
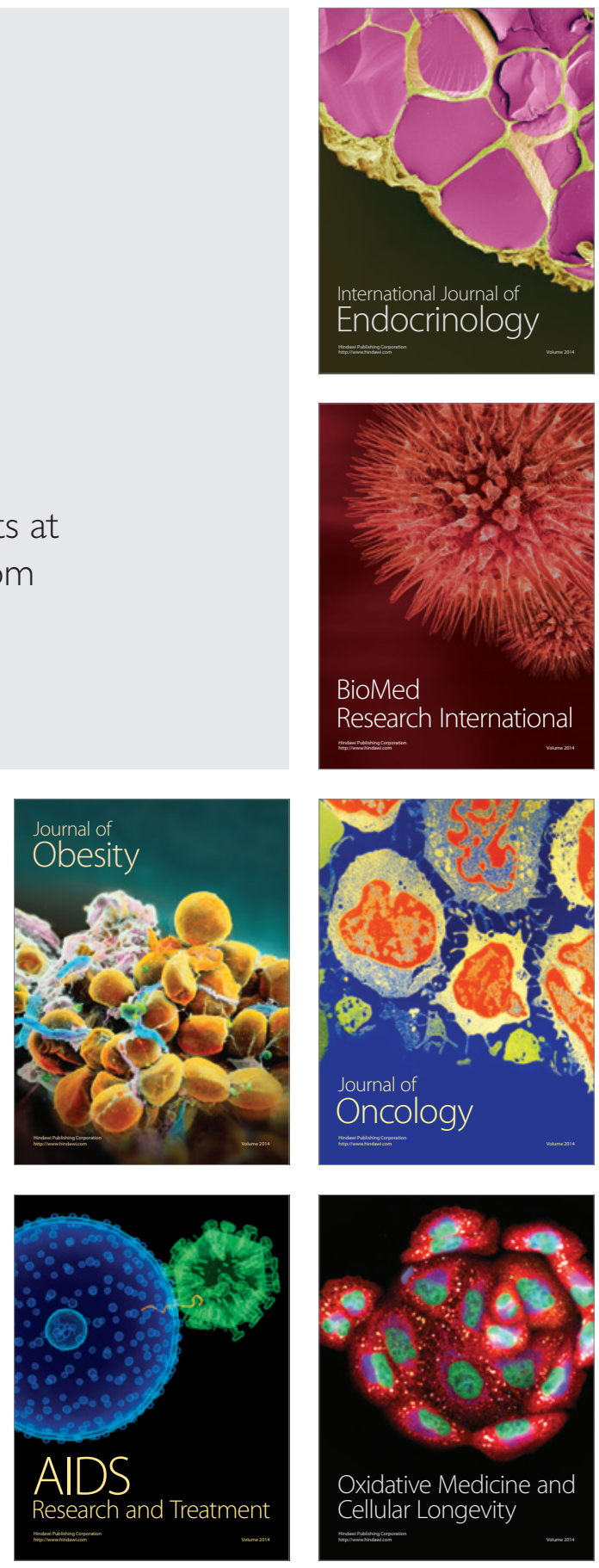